\title{
ESTADO DE DIREITO, SUPERAÇÃO DO POSITIVISMO E OS NOVOS RUMOS DO CONSTITUCIONALISMO
}

\section{RULE OF LAW, OVERCOMING OF POSITIVISM AND THE NEW DIRECTIONS OF CONSTITUTIONALISM}

\author{
${ }^{1}$ Adriana da Costa Ricardo Schier \\ ${ }^{2}$ Pedro Henrique Brunken Flores
}

\section{RESUMO}

O Direito passou por grandes evoluções no decorrer dos séculos. Primeiro, com o surgimento da Teoria Positivista que buscava afastar o Direito da moral, buscando-se um ideal de justiça. Após, com a superação de tal teoria e da necessidade de se pensar na proteção dos direitos humanos e fundamentais, o constitucionalismo surge e dele, após, decorre a teoria neoconstitucional, onde se dá maior atenção aos princípios estampados no mundo jurídico, possibilitando a interpretação da Constituição e das leis, a fim de garantir na maior medida possível a dignidade do ser humano, a proteção dos direitos fundamentais.

Palavras-chave: Positivismo; Constitucionalismo; Neoconstitucionalismo; Estado de Direito

\section{ABSTRACT}

The law has undergone major changes over the centuries. First, with the emergence of positivist theory that sought to set aside the law from morality, seeking an ideal of justice. Then, with the overcoming of such theory and the need to think about the protection of human and fundamental rights, constitutionalism arises and then the neoconstitucional theory, where it gives more attention to patterned principles in the legal world, enabling the interpretation the Constitution and laws, to ensure as far as possible the human dignity, the protection of fundamental rights.

Keywords: Positivism; Constitucionalism; Neoconstitucionalism; Rule of law

\footnotetext{
1 Pós-doutoranda em Direito Pontifícia Universidade Católica do Paraná, PUCPR - PR, (Brasil). Professora da graduação e do programa de Mestrado do Centro Universitário Autônomo do Brasil , UNIBRASIL - PR, (Brasil). Advogada.

${ }^{2}$ Mestrando em Direitos Fundamentais e Democracia pelo Centro Universitário Autônomo do Brasil, UNIBRASIL PR, (Brasil). Bolsista CAPES. E-mail: phbflores@gmail.com
} 


\section{INTRODUÇÃO}

O direito e consequente as formas de Estado passaram nos últimos séculos por grandes mudanças em um cenário contemporâneo. Se tem, no mundo moderno, uma nova concepção de mundo e, especialmente, do trato das relações sociais.

O Direito vem, nesse primeiro momento, com um caráter positivista bem demonstrado pela teoria de Hans Kelsen, tendo a lei como parâmetro regulador da sociedade. Mostra-se a importância da regulação do Estado e da sociedade a partir de uma agenda legal, respaldado no explícito nos códigos, na lei escrita. Afasta-se o Direito da moral, a fim de garantir, nesse momento histórico uma concepção de aplicação de justiça.

Todavia, com decorrer da história, levando-se em conta fatos históricos como, por exemplo, as grandes guerras mundiais, se clarifica a necessidade de se pensar o direito para além do estritamente escrito na lei, mostra-se uma clara importância do estudo dos princípios, bem como da incorporação dos tratados internacionais às legislações dos países.

Surgem, assim, constituições pautadas nesses princípios, preocupando-se com o bemestar das sociedades e com o respeito aos direitos humanos. A distinção entre direito e moral, entre o direito e outras ciências naturais como a sociologia e filosofia torna-se estreita.

Há, aqui, o fenômeno da Constitucionalização do Direito. No brasil, esse fenômeno torna-se mais evidente com a promulgação da Carta Constitucional de 1988, documento que se preocupou de forma bastante veemente com a proteção dos direitos fundamentais e humanos, com a obrigação de resguarda-los e concretizá-los da melhor maneira possível.

Essa constitucionalização se traduziu então no respeito das leis à Constituição. Se percebe a vinculação de todas as leis estatais, do Estado - Democrático e de Direito - brasileiro à Constituição. Com isso, novas características nessa concepção de Estado vem à tona, incluindo um papel mais ativo do Poder Judiciário que passa a ter a responsabilidade de, em sendo o caso, garantir o respeito às disposições constitucionais. A esse fenômeno se dá o nome de Controle de Constitucionalidade.

Essa compreensão do papel exercido pelo controle de constitucionalidade nos Estados Contemporâneos pressupõe a análise das atuais funções atribuídas aos chamados poderes 
públicos, no contexto de uma revisão da teoria da tripartição de poderes eminentemente vinculada à teoria da democracia.

Pois, afinal, desde o advento do Estado Liberal, faz parte da agenda política dos Estados Nacionais do Ocidente a busca pela limitação do uso do poder político em prol da consolidação de uma esfera pública que assegure o bem comum, traduzido, principalmente, no conteúdo garantístico dos direitos fundamentais.

Essa é a razão do presente trabalho. Demonstrar que a evolução do Estado de direito, a partir do fenômeno do constitucionalismo, permitiu esse controle do poder político pela esfera do judiciário, a partir da aplicação e interpretação dos princípios constitucionais. Podendo-se dizer que o Constitucionalismo evolui para uma nova face, o neoconstitucionalismo.

\section{O ESTADO DE DIREITO E O POSITIVISMO}

De início para o presente trabalho, trazer à baila concepções a respeito do Estado de Direito e do fenômeno jurídico do Positivismo são importantes, pois, afinal, é a partir desse momento e da então superação do positivismo que se torna possível falar em constitucionalismo e neoconstitucionalismo.

As Revoluções do século XVIII, os homens tornaram-se "livres" e, em certa medida, "iguais"3. Neste momento, o direito, até então instrumento de mera opressão ou legitimação de um estado sem limites, viabiliza-se como um canal de libertação (CLÈVE, 1988). O Estado não é mais o rei. É o povo no parlamento, é a busca de uma finalidade comum. O Estado, que era "tudo", inclusive absoluto, passa a ser o mínimo, passa a atuar somente onde e quando a sociedade permitir, ou seja, o Estado não interfere mais na vida, na esfera dos indivíduos (princípio liberal).

\footnotetext{
${ }^{3}$ Ver, sobre o tema do advento do Estado Liberal na perspectiva ora adotada, SCHIER, 2002.
} 
Certamente, as mudanças ocorridas na passagem do Estado absolutista para o Estado Liberal $^{4}$ não ocorreram desligadas de lutas sociais, políticas, jurídicas, econômicas e mesmo filosóficas ${ }^{5}$ contra o Estado Absolutista na sua dimensão de Estado de Polícia. Tem-se, aqui, uma verdadeira alteração paradigmática na história da humanidade. O homem passa a ser visto como sujeito capaz de construir sua história, determinando seu futuro a partir da razão. Passa a ocupar o centro do mundo, de forma livre e autônoma. É, enfim, esta percepção iluminista e humanista que marca o contexto ético no qual se desenvolve o liberalismo.

No campo da Teoria do Estado, esse é o cenário no qual surgem as concepções que identificam o Estado de Direito ${ }^{6}$.

De acordo com J. J. Gomes CANOTILHO, o conceito de Estado de Direito é informado por uma concepção filosófica que identifica um Estado no qual se respeita a liberdade ética do homem individual e se reconhece uma vinculação jurídica para os atos emanados do poder público. Segundo ele, este modelo de estado é uma exigência universal da razão, pois assegura a coexistência livre através do direito (CANOTILHO; MOREIRA, 1991, p. 356).

Ainda para este autor, a existência de uma Constituição é um pressuposto do Estado de Direito. Ela, nesta medida, apresenta-se como a ordem jurídico-normativa fundamental que vincula todos os poderes públicos (CANOTILHO; MOREIRA, 1991, p. 364) ${ }^{7}$. Lembre-se, em tempo, que a Constituição, neste contexto, apresentava-se como o estatuto jurídico do político, funcionando como instrumento de defesa dos direitos individuais dos homens perante o Estado ${ }^{8}$.

\footnotetext{
${ }^{4}$ Também trata da evolução do direito em relação aos períodos históricos, tanto no liberalismo, quanto no Estado Social, na perspectiva aqui adotada, SCHIER, 1999. p. 63-96.

${ }^{5}$ O que bem demonstra LEVY \& TIGAR, 1977. p. 227 e ss.

${ }^{6}$ Com efeito, ainda que seja possível identificar a gênese do Estado de Direito já nos séculos XVI e XVII, conforme aponta Simone GOYARD-FABRE (1999, p. 31), é certo que este modelo de Estado, com a figuração que lhe foi consagrada historicamente, desponta no contexto da Revolução Francesa.

${ }^{7}$ Deste pressuposto decorre que no Estado de Direito deve haver uma vinculação do legislador à Constituição. Assim, todas as leis editadas devem estar conforme aos ditames constitucionais. Além disso, todos os atos políticos e administrativos devem se conformar aos ditames constitucionais. Também em decorrência deste pressuposto, o autor refere a chamada 'reserva da constituição'. Por conta deste traço, determinadas questões só podem ser reguladas pela Constituição, o que é determinado a partir da definição do quadro de competências fixando o âmbito de atuação de cada ente federativo e de cada órgão público. Além disso, a reserva de constituição implica em que as restrições relativas ao âmbito dos direitos, liberdades e garantias devem ser feitas diretamente pelas normas constitucionais ou mediante lei, nos casos em que há autorização expressa na Constituição (CANOTILHO; MOREIRA, 1991, p. 364).

${ }^{8}$ Neste sentido, J. J. Gomes CANOTILHO e Vital MOREIRA (1991, p. 38-9) relacionam três traços que identificam a Constituição do Estado Liberal: “a) A constituição era considerada apenas, ou fundamentalmente, como estatuto
} 
A Constituição do Estado Liberal, então, apresenta-se destinada a conformar a sociedade negativamente, impondo limites aos poderes estatais, principalmente através da teoria da tripartição de poderes e do princípio da legalidade.

O princípio da tripartição de poderes, nessa dimensão clássica, fornece as bases teóricas para a limitação do poder soberano. Como se sabe, a partir da teoria de Montesquieu, as funções de fazer as leis (função legislativa), executar as diretrizes legais (função executiva) e controlar a sua aplicação (função judiciária), deixam de ser desempenhadas pelo Monarca e são distribuídas entre três órgãos: Poder Legislativo, formado por representantes do povo e encarregado de juridicizar a vontade geral, Poder Executivo - destinado a aplicação concreta das leis e Poder Judiciário - a quem cabia a função exclusiva de "dar a solução nos casos concretos".

As idéias até aqui desenvolvidas foram sintetizadas por Clèmerson Merlin CLÈVE 2000, p. 29-30) que refere:

\begin{abstract}
A proposta dos pensadores oitocentistas não era de, mais uma vez, atomizar o poder político, mediante a eventual destruição do aparato estatal. O Estado consiste, para esses pensadores, num mal. Mas num mal necessário. A proposta do Estado Constitucional era a de limitar o poder político, mantendo-o concentrado. E isto ocorreria da seguinte forma: primeiro, tratava-se de organizar o espaço político de tal maneira que o poder se encarregasse de controlar o próprio poder. Aqui reside o núcleo da teorização conducente à separação dos poderes; depois, deslocando a soberania das mãos do monarca para as mãos do povo ou da nação. Ocorre, neste passo, a transferência da titularidade do poder soberano (...). A separação de poderes corresponde a uma divisão de tarefas estatais, de atividades entre distintos órgãos, e aí sim, autônomos órgãos assim denominados de poderes.
\end{abstract}

As cartas constitucionais do liberalismo consagram, ainda, direitos, liberdades e garantias, na dimensão dos chamados direitos de defesa, que asseguram aos cidadãos a possibilidade de exigir a abstenção do Estado.

Para FERRAJOLI (2003, p. 15), tal contexto indica a refundação do Direito sobre o prisma do princípio da legalidade, valorando-se a segurança jurídica como garantia de certeza e

organizatório do Estado; b) a constituição era encarada apenas, ou principalmente, como limite da actividade do Estado; c) a constituição só interessava directamente aos cidadãos enquanto defesa de sua esfera de liberdade perante o Estado. (...) a constituição era, não a lei fundamental da ordem jurídica de uma colectividade politicamente organizada, mas sim e apenas o estatuto da organização política do Estado".

Revista Brasileira de Teoria e Constituição | e-ISSN: 2525-961X | Curitiba | v. 2 | n. 2 | p. 1208 - 1229 | Jul/Dez. 2016 
liberdade frente à arbitrariedade, caracterizando o que o autor denomina de Estado Legislativo de Direito.

No âmbito da Teoria do Direito, fez-se necessária a elaboração de um arsenal teórico capaz de fornecer subsídios para a compreensão do fenômeno jurídico nos moldes do liberalismo clássico, despontando, nesse contexto, o positivismo jurídico.

Neste panorama, a Ciência jurídica adota o caráter de disciplina cognitiva do Direito: é um discurso sobre um objeto, ou seja, é o discurso descritivo sobre o sistema jurídico (FERRAJOLI, 2003, p. 16).

Nos limites do presente trabalho não cabe uma abordagem exaustiva do positivismo jurídico, restringindo-se a análise deste tópico tão-somente às características centrais de tal doutrina. Pretende-se, com isso, apenas contextualizar o papel atribuído ao Judiciário, no período dominado pelas correntes positivistas, de modo a se compreender a aplicação dos seus no movimento do constitucionalismo e, posteriormente, verificar sua possível incidência no chamado neoconstitucionalismo, tomando como parâmetro as questões referentes ao ativismo judicial e à contenção da atividade jurisdicional.

Toma-se, por referência, as anotações de Luis Prieto SANCHÍS (1999), que analisa o positivismo sob o viés metodológico, teórico e ideológico.

$\mathrm{O}$ autor parte do pressuposto de que a tese central do positivismo é a neutralidade, "una aproximación avalorativa al concepto de Derecho, entendiendo que éste puede ser definido como um hecho, no como um valor (...) lo que lo define no es aquello que manda o prohibe, sino la forma de hacerlo" (SANCHÍS, 1999, p. 11-2). Tem-se, aqui, o positivismo como metodologia, tomado como um método de compreender que dá destaque à forma, ao modo pelo qual as normas adquirem validade e não ao seu conteúdo. Tem-se daí a clássica separação entre moral e direito.

Nesta seara, portanto, o Direito se define não em face de seu conteúdo, mas como um mecanismo que permite a organização do uso da força em sociedade (SANCHÍS, 1999, p. 13) ${ }^{9}$.

\footnotetext{
${ }^{9}$ Como o autor mesmo resume: "El contenido mínimo del positivismo metodologico se compone de estas dos ideas: que la existência de las normas no depende de que satisfagan algún particular valor moral, y que el derecho es siempre obra de decisiones humanas o, como suele decirse, que tiente uma origen social.”.
} 
Já o positivismo teórico reúne, por sua vez, teses independentes que se preocupam em determinar a natureza do direito, destacando-se aquelas que (i) vinculam o direito ao uso da força (SANCHÍS, 1999, p. 13); (ii) procuram explicar o direito pela fonte do objeto jurídico reduzindo o direito à lei produzida pelo Estado, (iii) concebem a norma como uma ordem dirigida aos indivíduos (SANCHÍS, 1999, p. 15) - teoria imperativista da norma - e, por fim, (iv) a idéia do direito enquanto um sistema - conjunto de regras que possuem uma unidade coerente, ausente de contradições.

Finalmente, refere o autor o positivismo como ideologia, explicando tal corrente a partir de dois referenciais: (i) o mais radical, que afirma que o direito representa o critério do justo e do injusto, de onde deduz-se a obrigação moral incondicionada de obediência ao direito e, também, (ii) o mais moderado, que sustenta que o direito, enquanto uma ordem regular de convivência, garante certos valores morais (segurança, certeza, previsibilidade das condutas, a paz), razão pela qual há uma certa obrigação de obediências às suas regras (SANCHÍS, 1999, p. 15).

Nesse modelo, então, a validade da norma é determinada a partir de um aspecto formal, ligado à competência da autoridade da qual emanou. Em outras palavras: a norma é valida desde que elaborada de acordo com as exigências do sistema normativo.

Com base em tais argumentos, a função jurisdicional assume contornos bem delineados. É reconhecido ao juiz, nesta medida, somente o papel de aplicador neutro da Lei. Como refere FERRAJOLI (2003, p. 16), o princípio da legalidade é a única fonte de legitimação da atividade jurisdicional.

Desponta, ainda, o princípio da independência judicial, entendido como mera obediência do juízo à lei: uma garantia de que os juízes não recebessem ordens de ninguém

de qualquer dos outros poderes, maxime, do executivo - quando da decisão dos casos concretos, postulando-se que isso só aconteceria se eles se limitassem a aplicar lógicodedutivamente (e não a mobilizar, por mediação de um discurso argumentativoprudencial e, portanto, interpelantemente ad hominem) uma legalidade geral e abstrata: apenas nessa hipótese a sentença proferida seria tão neutra, tão necessária, tão impessoal e tão objectiva (sic) como a própria lógica, uma vez que ela traduziria a apofântica concretização do seu pressuposto nuclear - da lei (BRONZE, 2002, p. 329). 
Admite-se, com isso, a possibilidade de se extrair da norma a verdade. Aqui, SANCHÍs (1999) identifica a teoria mecanicista da interpretação, calcada na idéia de subsunção ${ }^{10}$. Essa teoria parte da crença em uma interpretação neutra, objetiva e imparcial, que permitisse ao intérprete extrair do texto legal seu exato e real sentido, adotando-se uma postura formalista.

A tarefa de interpretação, portanto, atribuída ao juiz, resume-se a explicar, esclarecer, encontrar o sentido das palavras, permitir a reprodução fiel de um pensamento já exteriorizado, "mostrar o sentido verdadeiro de uma expressão; extrair, de frase, sentença ou norma, tudo o que na mesma se contém", é "revelar o sentido apropriado para a vida real, e conducente a uma decisão reta" (MAXIMILIANO, 1981, p. 9-10).

\section{O CONSTITUCIONALISMO}

A adoção dos postulados positivistas acima visitados, no entanto, não impediu que fossem adotados os principais cânones do movimento constitucionalista, ainda que, como sustenta Ricardo GUASTINI (2003, p. 55), na concepção liberal clássica a função da constituição restringia-se em limitar o poder político, sem que lhe fosse reconhecida a capacidade de produzir efeitos na vida social, a não ser "después de haber sido concretizada por leyes".

Assim, ainda que a partir de uma perspectiva mais restrita, fazem-se presentes as chamadas "condições de constitucionalização", ou seja, já é possível identificar a existência de uma constituição rígida, protegida por um sistema de garantia jurisdicional de seus postulados controle de constitucionalidade. Presente, ainda, a idéia de supremacia das normas constitucionais em face da legislação infraconstitucional determinando que "la Constitución es um limite a la legislación" (GUASTINI, p. 2003, p. 56).

\footnotetext{
${ }^{10}$ A adoção desta técnica foi amplamente admitida no Brasil. Por aqui, o livro clássico que trata do tema é, ainda, o de Carlos Maximiliano (Hermenêutica e aplicação do direito). Segundo o autor, "a aplicação do direito consiste no enquadrar um caso concreto em a norma jurídica adequada. Submete às prescrições da lei uma relação da vida real; procura e indica o dispositivo adaptável a um fato determinado. Por outras palavras: tem por objeto descobrir o modo e os meios de amparar juridicamente um interesse humano" (MAXIMILIANO, 1981, p. 6).
}

Revista Brasileira de Teoria e Constituição | e-ISSN: 2525-961X | Curitiba | v. 2 | n. 2 | p. 1208 - 1229 | Jul/Dez. 2016. 
Nesse diapasão, "a força normativa da constituição traduz-se na sua pretensão de regular juridicamente o estatuto organizatório dos órgãos do Estado separado da sociedade" (SCHIER, 2001, p. 55).

Tem-se, assim, uma supremacia formal da constituição. Destarte, nos moldes kelsenianos, as normas constitucionais apresentam-se como fonte de validade formal das normas infraconstitucionais e é esse o referencial que permite o controle de constitucionalidade a ser feito pelo Poder Judiciário.

Relembre-se que a atividade do juiz, ainda nesse momento, limita-se à subsunção dos fatos à norma, tem o juiz, no esquema tradicional da divisão de poderes, a função de (i) extrair das regras a verdade positivada pelo legislador (ii) identificar as hipóteses fáticas de aplicação da norma e (iii) subsumir a norma ao caso concreto.

Nesta medida, o controle de constitucionalidade restringe-se a verificar se a norma apreciada está de acordo com as regras constitucionais, principalmente do ponto de vista da produção normativa. É um controle absolutamente limitado, ou seja, o órgão ao qual a própria constituição atribui a competência para o controle das leis "apenas têm de verificar se aquilo que se apresenta com o sentido subjetivo de uma lei foi publicado como lei na folha legislativa, quer dizer, no documento impresso por ordem do governo. Para verificar se aquilo que é publicado como lei foi decidido pelo órgão que a Constituição considera competente, através do processo prescrito pela Constituição e com o conteúdo determinado pela mesma, (...)" (KELSEN, 1994, p. $303)$.

Nesta dimensão, o alcance do controle de constitucionalidade responde, em última análise, às exigências do sistema democrático no viés liberal: por um lado, assegura que as normas constantes na Carta Magna (que, por sua vez, também são restritas) sejam observadas pelo legislador infraconstitucional, mas, por outro lado, garante o caráter majoritário do princípio democrático, reconhecendo ao Legislativo, enquanto órgão representante da vontade da maioria, o papel de criar o direito. É uma opção clara pelo Poder Legislativo. 
Tem-se, assim, desenhados os contornos do Estado Liberal: um estado mínimo, abstencionista, organizado mediante uma Constituição rígida, que assegura a contenção do poder e garante direitos fundamentais.

A teoria da tripartição de poderes, nesta dimensão, assegura uma severa repartição entre as funções estatais, assegurando ao Poder Legislativo (órgão de representação popular) - a função - quase que exclusiva - de produzir o Direito. Consequência direta desta prevalência do Poder Legislativo é a adoção de um controle soft de constitucionalidade - centrado na verificação de validade da legislação infraconstitucional, limitando-se a tarefa do juiz à descoberta do direito positivado nas leis, tudo justificado mediante a adoção dos cânones do positivismo jurídico.

O sistema se legitima, então, em institutos que gravitam em torno da busca pela racionalidade formal: pretende-se a previsibilidade, a certeza e a segurança jurídica, "que consiste no fato de a decisão dos tribunais ser até certo ponto previsível e calculável, em os indivíduos submetidos ao Direito se poderem orientar na sua conduta pelas previsíveis decisões dos tribunais". (KELSEN, 1994, p. 279).

O modelo de Estado Liberal, contudo, não foi capaz de dar conta dos anseios das sociedades ocidentais. Seja por aspectos econômicos, ligados a alterações no modelo capitalista, seja em face de demandas sociais, o modelo liberal clássico foi substituído por estados organizados nos moldes do Estado Social. Com efeito, o capitalismo e o livre mercado não foram suficientes para assegurar uma real liberdade e igualdade aos indivíduos. O bem geral, ao contrário do que propunham os liberais clássicos, não foi atingido através da somatória dos bens individuais, conforme pretendia Adam Smith.

Segundo Jorge Reis NOVAIS (1987, p. 128), o Estado Social surge com o fim de resgatar a dimensão material do Estado de Direito, através da intervenção do Estado na sociedade, mediante prestações positivas voltadas a assegurar a todos o acesso a um núcleo de direitos fundamentais. E, além disso, afirma o autor que o caráter social desta forma de Estado implica na existência de uma atuação da sociedade no âmbito do poder público. Tem-se, deste modo, a socialização do Estado e a estadualização da Sociedade (princípio da socialidade).

Nesse contexto, a Constituição adquire um novo status, "tendencialmente positiva, pois (i) constitui e conforma a sociedade através da imposição de fins e tarefas aos poderes públicos e 
(ii) consagra, ao lado dos direitos negativos, direitos fundamentais de natureza positiva, que implicam direitos de participação e direitos de prestações, ou seja, direitos através do Estado" (SCHIER, 2001, p. 55).

Nesta perspectiva, de carta mínima, voltada a organizar o núcleo de poder das sociedades, a Constituição passa a ser o instrumento que ao tempo em que mantém os elementos estruturais do modelo liberal (Estado de Direito - tripartição de poderes e princípio da legalidade) igualmente atende as exigências de um Estado Democrático de Direito.

Prietro SANCHÍS (2003, p. 130), na perspectiva do Direito Constitucional, reconhece, nesse momento histórico, um avanço do chamado Constitucionalismo Clássico, pautado na busca pela rematerialização do direito. Para ele, há, com tal movimento, a incorporação de valores no texto constitucional, principalmente em torno do ideal de justiça (princípios).

Suzana POZOLLO (2003, p. 190) afirma, neste diapasão, que a superação do modelo de Estado legalista, típico do liberalismo clássico, principalmente com as Constituições do Pós-2 $2^{\mathrm{a}}$. Guerra, implicaram na adoção de um novo método de compreensão do fenômeno jurídico. Identifica, assim, uma sensível alteração nos ordenamentos jurídicos, fundados em Constituições que reconhecem como normas princípios de justiça, dotados de efetividade.

Ou seja, a alteração no objeto de estudo do Direito importa, igualmente, na modificação da Ciência Jurídica. Incidente uma nova concepção materializada de constituição, o positivismo e as técnicas de interpretação mecanicistas não dão conta de promover as soluções para os casos jurídicos.

Daí nasce a necessidade de se revisar a teoria da separação de poderes, a dimensão do princípio democrático, o método de compreensão e interpretação do Direito e, com isso, a dimensão do controle de constitucionalidade e a legitimação do sistema jurídico.

São essas as principais circunstâncias determinantes dos chamados movimentos “neoconstitucionalistas", ou as suas "ousadias”, como assenta Paulo Ricardo SCHIER (2005, p. $5)$. 


\section{OS NOVOS RUMOS DO CONSTITUCIONALISMO}

O novo momento do constitucionalismo contemporâneo, então, o chamado neoconstitucionalismo, estrutura-se através de um conjunto de teorias que, identificando uma alteração substancial no formato e no papel das constituições, buscam criar elementos para fundamentar um novo arsenal teórico de compreensão do direito.

Nessa linha de argumentação, Paulo Ricardo SCHIER (2005, p. 5) afirma que

Precisou o neo-constitucionalismo trazer a luz e as águas reparadoras ao mundo do Direito. Agora, falamos do pós-positivismo, da inevitável intervenção da moral na solução dos casos difíceis, da técnica da ponderação na aplicação do direito, no ingresso dos fatos e da realidade na própria estrutura da norma jurídica, reconhecemos certa liberdade interpretativa criativa aos magistrados, a intervenção de sua esfera de précompreensão no processo decisório, a união lingüística entre sujeito e objeto e, dentre outras conquistas, a afirmação da especial normatividade dos princípios.

Pode-se identificar, a partir de Luis Prieto SANCHÍS (2003, p. 123), os postulados centrais do que ele chama de uma Teoria do Direito calcada na perspectiva neoconstitucionalista: i) a presença da Constituição em todas as áreas jurídicas e em todos os conflitos relevantes onipotência da Constituição; ii) a coexistência de uma constelação plural de valores assegurados no texto constitucional; iii) há mais princípios do que regras; iv) há mais ponderação do que subsunção; v) onipotência judiciária em lugar da autonomia do legislador ordinário.

Como antes ressaltado, caracteriza o novo constitucionalismo a dimensão que permite reconhecer uma rematerialização da constituição, ou seja, é inegável que as atuais cartas constitucionais - ou o seu referencial de compreensão - são permeadas de valores, os quais serão positivados mediante os princípios jurídicos.

É nesse aspecto que Pietro SANCHIS (2003, p. 132) aponta o que ele denomina de onipotência da Constituição. Afirma, assim, que essa característica será determinada em face de seu conteúdo material, composto por valores, princípios fundamentais, diretrizes ao poder público, em razão do que dificilmente haverá uma questão jurídica relevante que não encontre tratativa dentro do texto constitucional, e, às vezes, distintas orientações. Ou seja, seria possível 
afirmar que por trás de cada preceito legal sempre haverá uma norma constitucional que o confirme ou que o contradiz - é o que o autor chama de irradiação do texto constitucional.

É esta dimensão principiológica que permite colocar "a Constituição como verdadeiro fundamento material de toda ordem jurídica, de modo que será possível sustentá-la como um Pacto dotado de verdadeira reserva de justiça". Com isso, "os princípios passam a caracterizar o próprio 'coração das constituições', iluminando a leitura de todas as questões da dogmática jurídica, que devem passar pelo necessário processo de filtragem constitucional axiológica" (SCHIER, 1999b, p. 3).

Nessa perspectiva axiológica, novamente SANCHÍS (2003) reconhece que há valores consagrados no texto constitucional que, por vezes podem levar a verdadeiras antinomias diante de casos concretos. Neste tópico, chega a afirmar que, com alguma porção de exagero, seria possível admitir que não existe norma substantiva da Constituição que não encontre frente a si outras normas capazes de fundamentar uma solução contrária para um dado caso concreto.

Tal circunstância, contudo, é resolvida em face da natureza das normas que integram a constituição neoconstitucionalista que, como antes referido, são de duas espécies: regras e princípios.

Desse modo, SANCHÍS (2003, p. 142) retoma a conhecida questão que diferencia a forma de solução de conflitos entre regras e colisão de princípios. Ou seja, parte da noção de que um conflito de regra se resolve pela regra do tudo ou nada, vinculada a questão a um juízo de validade. Já no caso dos princípios, mesmo em caso de colisão, a aplicação de um deles a um dado caso concreto não torna sem efeito aquele cuja aplicação resultaria em uma solução contrária.

Não por outro motivo, reconhece que os princípios (constitucionais ou não), exigem ferramentas específicas de interpretação, o que implica em outra questão pertinente ao neoconstitucionalismo: mais ponderação do que subsunção.

Da mesma forma, Suzana POZZOLO (2003, p. 193) afirma que diante de um ordenamento composto por princípios, necessária, ainda, a adoção de um novo método de interpretação, qual seja, uma técnica de ponderação, conectada à razoabilidade prática de 
instrumentos equitativos. Destarte, “el intérprete, en el fondo, deberá elegir entre la estricta legalidade y la justicia sustancial, adoptando la solución menos traumática y más compatible com la realidad (ocasional) y con el sistema jurídico em su conjunto, haciendo así prevalecer un o otro valor contingentemente relevante".

Para ALEXY (1993, p. 89), tem-se a ponderação quando "uno de los principios tiene que ceder ante el outro. Pero, esto no significa declarar inválido al principio desplazado ni que en el principio desplazado haya que introducir una clausula de excepción. Más bien lo que sucede es que, bajo ciertas circunstancias uno de los princípios precede al otro". Então, de acordo com o autor, a ponderação implica verificar qual dos interesses, que apresentam abstratamente o mesmo status constitucional, possui maior peso no caso concreto.

Portanto, o neoconstitucionalismo, ao admitir uma constituição aberta, dotada de força normativa, que impõe a realização dos valores nela positivados, vincula a atuação, positiva e ou negativa, do poder público, inclusive do Poder Judiciário.

Nesta corrente, então, o juiz assume um papel decisivo na construção do direito. Com efeito, impõe-se ao Poder Judiciário a tarefa de assegurar que os valores constitucionalmente positivados tenham eficácia social. O juiz, antes mero revelador da verdade contida nas leis emanadas do Poder Legislativo, é tomado como aquele capaz de contribuir para a construção do modelo de sociedade preconizado pela Carta Magna ${ }^{11}$.

Exige-se, portanto, que o juiz procure, “à vista dos resultados da Ciência do Direito, assumir um compromisso efetivo com as reais aspirações das bases sociais” (COUTINHO, 1993, p. 43).

Tem-se, como se observa, uma alteração no esquema tradicional da divisão de poderes dentro do arcabouço do Estado. Com efeito, reconhecer ao Poder Judiciário a atividade criadora da lei implica em flexibilizar a divisão de poderes, alternando-se a estrutura inicial criada a partir dos postulados de Montesquieu.

\footnotetext{
${ }^{11}$ No Brasil, o chamado movimento do direito alternativo tomou a frente na defesa do papel do judiciário, desde a década de 1980, realizando verdadeiro combate ao positivismo-formalista-normativista e atribuindo ao juiz a tarefa de garantir os valores democráticos.
}

Revista Brasileira de Teoria e Constituição | e-ISSN: 2525-961X | Curitiba | v. 2 | n. 2 | p. 1208 - 1229 | Jul/Dez. 2016. 
Neste sentido, Alfonso García FIGUEROA (2003, p. 167) ressalta que o neoconstitucionalismo transfere o papel de protagonista da história política do Legislativo para o Judiciário.

Tem-se, aqui, o Juiz Hércules, criado por DWORKIN, capaz de resistir ao canto das sereias posto pelas condições concretas que permeiam os casos difíceis e chegar à solução correta $^{12}$.

O juiz é reconhecido, então, como legislador concorrente, cuja atividade visa a modelagem da lei de acordo com os conteúdos da Constituição (SANCHÍS, 2003).

Amplia-se, então, ao máximo, o controle de constitucionalidade, reconhecendo que a última palavra cabe ao Poder Judiciário: são os juízes os sujeitos capazes de verificar se as leis estão em conformidade com as normas constitucionais, numa perspectiva mais ampla do que aquela aceita no modelo positivista.

FERRAJOLI (2003, p. 18), no que se refere ao tema do controle da atividade legislativa pelo poder judiciário afirma que o papel do juiz, no neoconstitucionalismo "es aplicar la ley solo si es constitucionalmente válida, y cuya interpretación y aplicación son siempre, por esto, también um juicio sobre la ley misma que el juez tiene el deber de censurar como inválida mediante la denuncia de su inconstitucionalidad (...)" Segundo ele, há uma dimensão pragmática e uma responsabilidade cívica no exercício da atividade jurisdicional.

Neste panorama, contudo, despontam questões quanto à legitimidade democrática das decisões, principalmente porque se rompe com o esquema clássico do liberalismo, calcado no princípio da legalidade e na promessa de segurança jurídica.

Com efeito, nas teorias que abandonam - ao menos em tese - os postulados positivistas, cresce de importância a discussão sobre a segurança jurídica, especialmente na matéria referente à aplicabilidade dos princípios. É o que aponta, por exemplo, FIGUEROA (2003, p. 167) que afirma que "Esta transferência de poder hacia el Judicial ha sido considerada por algunos como uma grave lesión del principio democrático. Es objetivo prioritário del Estado de Derecho la

\footnotetext{
${ }^{12}$ A figura do juiz Hercules pode ser encontrada no livro Levando os Direitos a Sério de Ronald Dworkin, onde o personagem seria um juiz com tempo e conhecimentos inesgotáveis, ou seja, o Juiz ideal (DWORKIN, 2002).
} 
restricción del poder suscetible de um ejercicio arbitrario y el Estado Constitucional pretende reforzar esta restricción com la incorporación de ciertos derechos, que deberían significar una restricción del poder del legislador y, transitivamente, del juez".

As críticas apontam, ainda, que a técnica da ponderação levaria a um decisionismo, de cunho subjetivista, ou seja, que as decisões seriam tomadas com base em juízos preconcebidos do aplicador do direito, ou firmadas meramente em suas opiniões pessoais.

Coloca-se, em xeque, portanto, a legitimidade das decisões, tomando-se como afronta à democracia a possibilidade de um controle amplo da atuação do Poder Legislaitvo pelo Poder Judiciário, tal como ressalta Juan Carlos BAYÓN (2003, p. 214): “qué legitimidad tienen jueces no representativos ni politicamente responsables para invalidar decisiones de um legislador democrático. En suma: si como ideales morales se parte no sólo de derechos, sino también del valor de la democracia, entonces el camino hacia el constitucioanalismo es quizá menos llano de lo que parece."

Em suma, é inegável que não é mais possível aplicar os postulados típicos do positivismo jurídico, com o intuito de assegurar a segurança e certeza jurídicas. Isto porque o próprio positivismo mostrou-se, do ponto de vista da teoria política, incapaz de concretizar os valores democráticos se pensados a partir de uma concepção material. Por outro lado, partindo-se da teoria do direito, a estrutura de norma jurídica desta corrente teórica não fornece subsídios para a devida compreensão dos princípios que, agora, inegavelmente, integram a constituição, dotados de força normativa.

Não há mais como admitir, portanto, uma rígida separação entre direito e moral, ou imaginar um juiz neutro e passivo, que repudia os fatos da vida na aplicação do direito ou, ainda, continuar a defender que as opções do legislador devem prevalecer sobre as decisões judiciais, com base no discurso da democracia representativa formal.

Porém, rompido o sistema clássico da tripartição de poderes, como conferir legitimidade às decisões? Por certo, não há mais argumento para fundar a legitimidade do direito no princípio da legalidade. Até porque, em um dado caso difícil, é possível que o princípio da legalidade seja ponderado em face de outros princípios. 
Essa discussão remete ao cerne da questão do deslocamento do eixo da Teoria do Direito para a Teoria da Argumentação proposta pelo neoconstitucionalismo. Dado o caráter de abertura axiológica dos princípios consagrados na constituição, várias respostas poderão ser consideradas corretas do ponto de vista normativo (correção normativa) ${ }^{13}$ e assim o problema se torna o de saber qual é a melhor decisão no plano da validez factual. É neste momento que toma corpo a emergência da moral como fator a ser considerado ou não na solução dos casos concretos.

É neste ponto que divergem procedimentalistas e substancialistas. a legitimidade das decisões, agora, poderá ser conferida em duas dimensões: a do procedimento - o que assegura a legitimidade das decisões, para tais correntes, é o procedimento utilizado para que se chegue a elas ou a do conteúdo - a aplicação do direito se legitima quando faz reverência ao conteúdo que traduzem os valores mais caros positivados nos princípios constitucionais.

Sem adentrar na calorosa discussão que divide os atuais autores em procedimentalistas e substancialistas, a qual não tem espaço nos limites do presente trabalho, é possível pontuar, contudo, que tais autores não são imunes à preocupação em manter-se o pacto democrático, assegurando, com isso, o papel fundamental que é reconhecido, pelas constituições, ao poder legislativo. A questão central, contudo, é que no atual estágio do constitucionalismo, o papel de representar a vontade popular não se extingue no Poder Legislativo, mas impõe, inclusive ao Poder Judiciário, uma atuação comprometida com os valores consagrados no texto constitucional que deverão, por sua vez, refletir a vontade do povo, para lembrar do conceito de ROUSSEAU.

Ou seja, "não se está a defender a substituição do Legislador pelo Poder Judiciário. O que se está evidentemente a defender é a criação de mecanismos que eventualmente somem a contribuição vinda das técnicas políticas com aquelas provenientes das técnicas jurídicas (...)" (CLÈVE, 2001, p. 56).

Certamente, as teorias desenvolvidas pelos autores chamados neoconstitucionalistas não pretendem, ao contrário do que já sustentado por inflamados críticos, criar uma "panacéia", nem

\footnotetext{
${ }^{13}$ a despeito de Dworkin que sustenta que o juiz Hércules é capaz de encontrar a solução correta para o caso concreto (DWORKIN, 2002).
} 
se resume em obra de americanófilos ou germanófilos que pretendem aplicar os institutos do direito alienígena sem adaptá-los às realidades concretas de seus países ${ }^{14}$.

É bem verdade que no Brasil a aplicação apressada de certos postulados do neoconstitucionalismo por alguns juízes permitiu a emergência de decisões que, em nome de uma equivocada ponderação de princípios, acabam por olvidar os valores da própria Constituição Federal, pondo em risco as garantias mais caras do sistema democrático.

Por isso é que se tem discutido tanto o papel ativista do judiciário, principalmente no tema do controle de constitucionalidade.

\begin{abstract}
Mas, não se pode olvidar, por outro lado, que nós, que aprendemos a encontrar na lei a expressão da vontade geral; que aprendemos a localizar na lei a defesa da sociedade contra o arbítrio do poder público; nós que aprendemos a ver a lei como uma espécie de declaração de direito, de um direito encontrado pelo debate racional ocorrente no seio do parlamento, vamos nos surpreender com a descoberta que o Legislador, feito exatamente para proteger o cidadão, ele mesmo pode ser o veículo da opressão, ele mesmo pode ser o veículo da quebra dos direitos fundamentais, ele mesmo pode ser o violador da constituição (CLÉVE, 2001, p. 53).
\end{abstract}

Então, ao invés de promover uma crítica à adoção das propostas neoconstitucionalistas, defendendo, novamente, um papel de absoluta contenção da atividade do poder judiciário, com a esperança em se obter segurança jurídica, presencia-se um momento em que se faz imprescindível a coerência teórica dos operadores do direito: aplicar a técnica da ponderação, ou os postulados da teoria da argumentação, implica, igualmente, em admitir os limites propostos por tais referenciais teóricos.

Ou seja, é preciso verificar que a concepção aberta da Constituição, vinculada à noção de aprendizagem, não impede a existência de definição quanto a conteúdos "constitucionalmente necessários” ou “constitucionalmente impossíveis" (BACELLAR FILHO, 1998, p. 144) 15 .

\footnotetext{
${ }^{14}$ Veja-se a crítica de Jacinto Nelson de Miranda COUTINHO, analisando as recentes decisões do Poder Judiciário Paranaense na concessão de remédios para tratamentos de saúde: "Não serve, por seu turno, como argumento sustentável e diante da situação concreta, a panacéia do momento, ou seja, a ponderação de princípios, muito ao gosto de americanófilos e germanófilos, ..., que insistem em fazer direito comparado sem o menor denominador comum." (COUTINHO, 2006, p. 6, no prelo.)

${ }^{15}$ Conforme refere Romeu Felipe Bacellar Filho, "A abertura da norma constitucional, a estrutura principiológica não impede, porém, a existência de conteúdos 'constitucionalmente necessários' e 'constitucionalmente
} 
$\mathrm{Na}$ análise do caso, o aplicador do direito deve estabelecer uma relação de precedência condicionada, ou seja, esclarecer quais são as condições que implicam na escolha, naquela situação, da aplicação de um dos princípios e não de outro. É a partir da argumentação racional que se poderá exercer o controle das decisões judiciais - sempre fazendo-se reverência aos valores consagrados pelo princípio democrático.

Afinal,

a segurança jurídica não depende apenas do método de aplicação do direito e de solução de colisões entre direitos fundamentais. Crer que isso seria possível seria partilhar de um otimismo metodológico quase ingênuo. Imaginar que exista alguma possibilidade de aplicação do direito que esteja protegida contra algum tipo de subjetivismo do intérprete seria uma ingenuidade. Mesmo nos casos de 'simples' subsunção, nos quais muitos imaginam haver uma simples operação lógico-formal, o grau de liberdade do intérprete/aplicador do direito não é necessariamente pequeno. Embora a subsunção seja, de fato, um método em que a conclusão deve decorrer logicamente das premissas, a própria fundamentação dessas premissas e a interpretação dos termos nela contidos não é mais um processo lógico. Nesse âmbito, o grau de racionalidade possível não é diferente daquele presente no sopesamento ou na fundamentação de qualquer proposição jurídica (SILVA, 2009, p. 149).

$\mathrm{Na}$ linha do que se pretendeu nos limites do presente trabalho, então, parece ser possível sustentar que "a verdadeira previsibilidade da atividade jurisdicional se dá a partir de um acompanhamento cotidiano e crítico da própria atividade jurisdicional. Tal acompanhamento é tarefa precípua da doutrina jurídica. É papel dos juristas exercer um controle social da atividade jurisdicional" (SILVA, 2009, p. 149).

\section{CONSIDERAÇÕES FINAIS}

As discussões a respeito do neoconstitucionalismo são de ampla magnitude. A razão do presente trabalho é demonstrar a evolução do positivismo ao constitucionalismo e ao, então,

impossíveis'. Aqui, reside a capacidade de excluir-se os conteúdos incompatíveis com as normas constitucionais principiológicas e exigir-se outros necessários.” (BACELLAR FILHO, 1998. p. 144).

Revista Brasileira de Teoria e Constituição | e-ISSN: 2525-961X | Curitiba | v. 2 | n. 2 | p. 1208 - 1229 | Jul/Dez. 2016 
neoconstitucionalismo, buscando clarificar a necessidade do se pensar o direito para além da simples aplicação da lei.

Mais do que isso, procurou-se mostrar que o neocontitucionalismo vem de encontro com as necessidades contemporâneas do direito, com a necessidade de se proteger e concretizar os direitos fundamentais dos cidadãos. Aqui justifica-se o papel do Poder Judiciário que ascende de mero aplicador da lei na corrente positivista, para o papel de intérprete, junto com os demais poderes, da Constituição e com competência para, também, zelar pelos direitos fundamentais.

É certo que essa evolução ocorre com a vinda do constitucionalismo e com a mudança na interpretação do direito, valendo-se agora da argumentação jurídica na busca dos ideais constitucionais. Essas afirmações não podem levar ao entendimento de que há uma violação de competência e que o juiz está acima dos outros poderes, possuindo super-competências.

O neoconstitucionalismo se justifica ante a necessidade de se pensar o direito para os cidadãos, para a busca do maior grau de fruição dos direitos fundamentais. Permite a interpretação das leis mediante o uso de princípios para a concretização do Direito como um todo. Não há perfeição, mas sim uma nova forma de se teorizar.

Por óbvio que há, ainda, uma necessidade de se buscar a formação de operadores jurídicos comprometidos em concretizar os valores plasmados no texto constitucional, seja como controladores das decisões - num processo dialógico de convencimento - seja como magistrados, na solução de casos fáceis e difíceis. Não há teoria que por si só dê conta de assegurar a concretização de uma sociedade livre, justa e democrática.

\section{REFERÊNCIAS BIBLIOGRÁFICAS}

ALEXY, Robert. Teoría de los derechos fundamentales. Madrid: Centro de Estudios Constitucionales. 1993.

BACELLAR FILHO, Romeu Felipe. Princípios constitucionais do processo administrativo disciplinar. São Paulo: Max Limonad, 1998.

BRONZE, Fernando José. Lições de introdução ao Direito. Coimbra editora. 2002. 
CANOTILHO, J. J. Gomes; MOREIRA, Vital. Fundamentos de direito constitucional. Coimbra: Coimbra, 1991.

Carlos MAXIMILIANO. Hermenêutica e aplicação do direito. Rio de Janeiro: Forense, 9. Ed., 1981.

CLÈVE, Clèmerson Merlin. Atividade legislativa do poder executivo. 2. ed. São Paulo: RT, 2000.

, Clèmerson Merlin. Controle de constitucionalidade e democracia. In: Constituição e democracia. Antonio g. Moreira Maués (org.). São Paulo: Max Limonad, 2001.

, Clèmerson Merlin. O direito e os direitos, São Paulo: Acadêmica, 1988.

COUTINHO, Jacinto Nelson de Miranda. Da política pública ditada pelo poder judiciário no tocante à saúde pública. 2006.

, Jacinto Nelson de Miranda. O papel do novo juiz no processo penal. In: Direito alternativo. Seminário nacional sobre o uso alternativo do direito. Rio de Janeiro : 1993, pp. 3343.

DWORKIN, Ronald. Levando os direitos a sério. São Paulo. Martins Fontes. 2002.

FERRAJOLI, Luigi. Pasado y futuro del estado de derecho. In: CARBONELL, Miguel (org.). Neoconstitucionalismo (s). Madrid: Editorial Trotta, 2003, pp. 13-29.

FIGUEROA, Alfonso Jaime García. La teoria del derecho em tiempos del constitucionalismo. Neoconstitucionalismo(s). Miguel Carbonell Sánchez (coord). Editoria Trotta. España. 2003. p. 159-186.

GOYARD-FABRE, Simone. Os princípios filosóficos do direito político moderno. Tradução de: Irene A. Paternot. São Paulo: Martins Fontes, 1999.

GUASTINI, Riccardo. La constitucionalización del ordenamiento jurídico: el caso italiano. In: CARBONELL, Miguel (org.). Neoconstitucionalismo (s). Madrid: Editorial Trotta, 2003, pp. 13-29.

KELSEN, Hans. Teoria pura do direito. São Paulo: Martins Fontes, 1994.

LEVY, M. R. \& TIGAR, M. E.. O direito e a ascensão do capitalismo. Rio de Janeiro: Zahar Editores, 1977. 
MOHÍNO, Juan Carlos Bayón. Derechos, democracia y constitución. In: CARBONELL, Miguel (org.). Neoconstitucionalismo(s). Editorial Trotta. España. 2003. p. 211-238.

NOVAIS, Jorge Reis. Contributo para uma teoria do estado de direito: do estado de direito liberal ao estado social e democrático de direito. Coimbra: Coimbra, 1987.

POZZOLO, Suzanna, Un constitucionalismo ambiguo. In: CARBONELL, Miguel (org.). Neoconstitucionalismo (s). Madrid: Editorial Trotta, 2003, pp. 187-210.

SANCHÍS, Luis Prieto. Constitucionalismo e positivismo. Cidade do México: Distribuiciones Fontamara, 2. ed., 1999.

SANCHÍS, Luis Prieto. Neoconstitucionalismo y ponderación judicial. In: Miguel Carbonell Sánchez (coord). Neoconstitucionalismo(s). Editorial Trotta. España. 2003. p. 123-158.

SCHIER, Adriana da Costa Ricardo. A participação popular na administração pública. Rio de Janeiro: Renovar, 2002.

SCHIER, Paulo Ricardo. Anotações nucleares de direito constitucional. Curitiba: Juruá, 2001. , Paulo Ricardo. Filtragem constitucional. Porto Alegre: SAFE, 1999 b.

, Paulo Ricardo. Notas para uma introdução à racionalidade do direito constitucional. Verba Iuris v. 1, n 08, Curitiba: Editora Universitária Champagnat, 1999a.

, Paulo Ricardo. Novos desafios da filtragem constitucional no momento do neoconstitucionalismo. Revista eletrônica de direito do estado. Salvador. Instituto de Direito Público da Bahia, n. 4, outurbo/novembro/dezembro, 2005. Disponível em: www.direitodoestado.com.br. Acesso em: 23 set. 2016.

SILVA, Virgílio Afonso da. Direitos fundamentais: conteúdo essencial, restrições e eficácia. São Paulo. Malheiros, 2009. 